
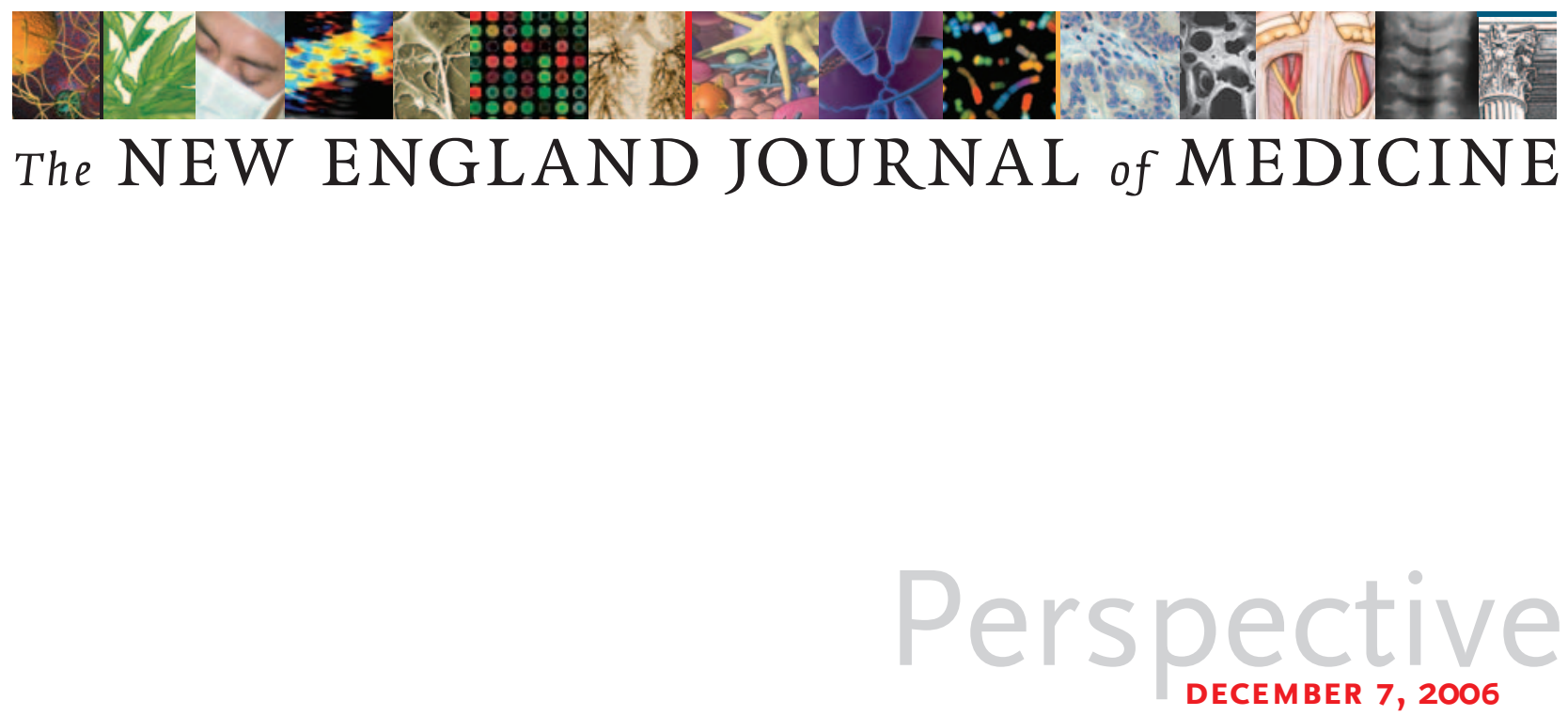

\title{
The Ethics and Politics of Compulsory HPV Vaccination
}

James Colgrove, Ph.D., M.P.H.

\section{n September 12, 2006, 3 months after the Food and Drug Administration licensed a vaccine against human papillomavirus (HPV), Michigan lawmakers became the first in the United States}

to propose that vaccination be compulsory for girls entering sixth grade. Parents who objected would be able to opt out of the requirement under the same provisions that apply to other vaccinations. The bill passed the state senate by an overwhelming margin a week later and awaits consideration by the house. Other states are likely to follow Michigan's lead.

The development of Gardasil, Merck's HPV vaccine, is of major public health importance. The vaccine protects against four strains of HPV, the most common sexually transmitted disease in the United States, including the two strains that cause most cases of cervical cancer. More than 6 mil- lion people in this country become infected with HPV every year, and nearly 10,000 women are diagnosed with cervical cancer. Because the vaccine has the greatest benefit when it is given before a person becomes sexually active, the Advisory Committee on Immunization Practices of the Centers for Disease Control and Prevention recommended that it be given routinely to girls at 11 or 12 years of age; it is not yet approved for use in boys. The committee took no position on whether vaccination should be required by law; such policy decisions are made by individual states.

Moves to make the vaccine compulsory are sure to ignite a new round of polarizing debates.
Controversy over the product began before it was licensed, when some religious conservatives expressed concern that the availability of a vaccine against a sexually transmitted disease would undermine abstinence-based prevention messages. Advocacy groups such as Focus on the Family ultimately came to support availability of the vaccine, but they remain opposed to mandating its use. In their view, such a requirement constitutes an attempt by the secular state to force a child to undergo an intervention that may be irreconcilable with her family's religious values and beliefs.

It is a mistake, however, to view the contrasting stances on HPV-vaccine mandates as solely, or even primarily, evidence of a conflict between science and religion. A more complicated dynamic will shape the ongoing discussion.

On one side, support for legal 
requirements is strongly influenced by the perception of HPV as a women's health issue. The severe consequences that the disease may have for women lends urgency to the effort to maximize use of the vaccine through all policy means, including mandates. Women in Government, a Washington-based, bipartisan organization of female legislators, is leading a push to make HPV vaccination compulsory in every state. The group has issued recommendations for ensuring that the vaccine is accessible and affordable, including a recommendation that states add it to their Medicaid programs and encourage private health plans to cover it. The group follows in the tradition of breast-cancer activists, who have mobilized through many political channels to combat an illness that disproportionately burdens women.

On the other side, opposition to mandates will come from a far wider range of constituencies than just religious conservatives worried about threats to teenagers' sexual abstinence. Vaccine requirements - even generally wellaccepted laws covering "classic" childhood diseases such as polio, measles, and pertussis - have been resisted in recent years on a wide range of philosophical, political, scientific, and ideological grounds.

During the past two decades, in the face of a sharp increase in the number of recommended pediatric vaccines, unproven theories alleging connections between vaccines and illnesses including autism, diabetes, and multiple sclerosis have been spreading. A social movement involving diverse participants has challenged the safety of vaccination and mounted attacks in courtrooms and legislatures on compulsory vaccina- tion laws. Forty-eight states allow parents who object to vaccination on religious grounds to excuse their children from requirements, and 20 of those states also allow exemptions for parents who have secular philosophical concerns. ${ }^{1}$ Approximately 1 to $3 \%$ of U.S. children are excused by their parents from vaccine requirements, though the rate varies from state

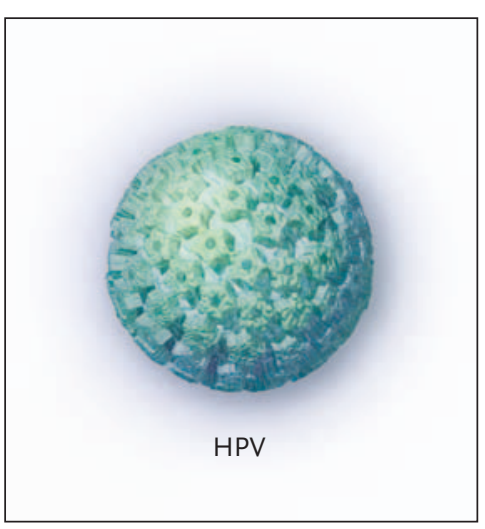

to state; schools in a few communities have exemption rates as high as 15 to $20 \%$. Activists have sought to liberalize the circumstances under which parents may opt out of vaccine requirements, a trend that reflects the wide variation in people's reasons for rejecting vaccines: devotion to "natural" or alternative healing, libertarian opposition to state power, mistrust of pharmaceutical companies, belief that vaccines are not as safe as experts claim, and conviction that children receive more shots than are good for them. ${ }^{2}$

Laws making vaccination compulsory raise unique ethical and policy issues. High levels of herd immunity protect all members of the community, including those who cannot receive vaccines because of medical contraindications. This protection provides a justification for compulsion. The availability of religious or philosophical exemptions mitigates concern about governmental intrusion on individual decision making. Opinions vary, however, about the permissible scope of exemptions. Data show that schools with exemption rates as low as 2 to $4 \%$ are at increased risk for disease outbreaks and that children who have been exempted from vaccine requirements have a much greater risk of acquiring infectious diseases than their vaccinated peers. ${ }^{1}$ Minors have a right to be protected against vaccinepreventable illness, and society has an interest in safeguarding the welfare of children who may be harmed by the choices of their parents or guardians.

Bioethicists, who generally hold the values of patient autonomy and informed consent to be preeminent, tend to be skeptical about compulsory vaccination laws. Not surprisingly, some have expressed wariness about or opposition to mandating HPV vaccination. ${ }^{3,4} \mathrm{Be}-$ cause HPV is not casually transmissible, they argue, there is a less compelling rationale for requiring protection against it than against measles or pertussis, for instance; in the absence of potential harm to a third party, such laws may be considered unacceptably paternalistic. Similar concerns have been raised about schoolbased requirements for vaccination against hepatitis $B$ : because the virus spreads primarily among sexually active people and injection-drug users, some parents argued that the vaccine should be given only to those groups rather than to all children. Such targeting of the vaccine, however, proved to be less effective than universal vaccination in reducing the incidence of the disease.

A large body of evidence demonstrates that school-based laws are an effective and efficient way 
of boosting vaccine-coverage rates. Requiring HPV vaccination by law will almost certainly achieve more widespread protection against the disease than will policies that rely exclusively on persuasion and education. In the view of advocates, this effectiveness provides a clear justification. "The only way to ensure that as many girls as possible receive the HPV vaccine is to require it before they enter middle school," said Beverly Hammerstrom, the Michigan state senator who introduced the legislation. Whether such a mandate might extend to boys, should the product be approved for such use, remains uncertain.

A critical question is whether achieving a higher level of coverage justifies the infringement on parental autonomy that compulsory vaccination inevitably en- tails. Different ethical frameworks that accord varying weights to communitarian and individualistic values will lead to contrasting answers to this question.

Ethical and epidemiologic analyses are essential to decisions about mandating the HPV vaccine; so are political calculations. Any new vaccine that a state adds to its list of requirements must be judged in the context of both the increasingly lengthy and complex regimen of vaccines that children now receive and the possibility that additional mandates may inflame grassroots opposition, be it religious, philosophical, or ideological. ${ }^{5}$ Although issues of religion and adolescent sexuality have dominated the discussion, the move to require HPV vaccination raises broad questions about the acceptability of mandatory pub- lic health measures, the scope of parental autonomy, and the role of political advocacy in determining how preventive health measures are implemented.

Dr. Colgrove is an associate research scientist at the Center for the History and Ethics of Public Health, Department of Sociomedical Sciences, Mailman School of Public Health, Columbia University, New York.

1. Salmon DA, Teret SP, Maclntyre RC, Salisbury D, Burgess MA, Halsey NA. Compulsory vaccination and conscientious or philosophical exemptions: past, present, and future. Lancet 2006;367:436-42.

2. Colgrove JK. State of immunity: the politics of vaccination in twentieth-century America. Berkeley: University of California Press, 2006.

3. Zimmerman RK. Ethical analysis of HPV vaccine policy options. Vaccine 2006;24: 4812-20.

4. Lo B. HPV vaccine and adolescents' sexual activity. BMJ 2006;332:1106-7.

5. Temte JL. Should all children be immunised against hepatitis A? BMJ 2006;332: 715-8.

\section{Exploring the Uses of RNAi - Gene Knockdown and the Nobel Prize}

René Bernards, Ph.D.

The Nobel Prize in Physiology

or Medicine was awarded this year to Andrew Fire (Stanford University School of Medicine) and Craig Mello (University of Massachusetts Medical School) for their discovery of a new form of gene silencing. Nearly 9 years ago, Fire and Mello and their colleagues reported that exposing cells of the nematode Caenorhabditis elegans to double-stranded RNA resulted in specific and efficient gene silencing. ${ }^{1}$ They also observed that double-stranded RNA is far more potent than sense or antisense RNA in silencing the gene that shares its sequence, and they dubbed the silencing process "RNA interference" (RNAi). Because RNAi rarely leads to the complete abrogation of gene expression, its effect is often described as a "knockdown" of gene expression. At first glance, RNAi seems similar to the antisense approach to gene silencing, but it is far more effective and has a different mechanism.

In plants and nematodes, the introduction of long doublestranded RNA into a cell leads to its cleavage into shorter fragments. These fragments are powerful silencers of gene expression and are therefore called "small interfering RNA" (siRNA). They are recruited into a protein complex that positions the antisense strand so that it acts as a snare for the RNA transcript to which it is complementary. Once bound to this snare, the RNA transcript is cleaved by the complex and is degraded (see diagram). In lower organisms, RNAi is thought to function as a primitive immune system, protecting against viruses (which often generate doublestranded RNA as replication intermediates) and transposable elements (also known as "jumping genes").

In most mammalian cells, long double-stranded RNA provokes an interferon response as part of an antiviral defense. This interferon response induces a global shutdown of protein synthesis, thus precluding the use of long doublestranded RNA for specific gene silencing. This obstacle can be overcome by using short doublestranded RNA (less than 30 base pairs in length), which evades the radar of the mammalian interfer- 